\title{
A Sintered and Sulfidized Equilibrated Aggregate from an Interplanetary Dust Particle
}

\author{
Zack Gainsforth $^{1}$, Andrew Westphal ${ }^{1}$ and Christine Jilly-Rehak ${ }^{2}$ \\ ${ }^{1}$ University of California at Berkeley, Berkeley, California, United States, ${ }^{2}$ Stanford University, Stanford, \\ California, United States
}

Heating processes in the early solar nebula are presumed to have melted precursor dust to create igneous objects called equilibrated aggregates (EAs). EAs range from $<1 \mu \mathrm{m}$ up to $\sim 100 \mu \mathrm{m}$, and show textures indicative of melting and formation of minerals under a variety of conditions ( $\left.\mathrm{fO}_{2}, \mathrm{~T}, \mathrm{P}\right)$. In this work, we study an EA from an interplanetary dust particle (L2071 cluster 12, "Humpty and Dumpty") captured by a stratospheric flight over North America in 2008. We prepared it using a Focused Ion Beam (FIB), and examined it using the TitanX Transmission Electron Microscope (TEM) at the Molecular Foundry in Berkeley, CA. Figure 1A shows the EA with a pyrrhotite/metal core which is Fe-rich on the left (red), and Ni-rich on the right (blue), and silicates (green). The small boxed area contains fine-grained silicates also shown in Figure 1B. Figure 1B is colored using Non-negative Matrix Factorization (NMF) of the EDS map. Olivine and kosmochloric [Joswiak] clinopyroxene (CPX) crystals are embedded in an Al-, Si-rich glass. The Mg\# varies from 73 to 83 depending on the phase. See compositions in Table 1. Phase identifications are based on EDS with the exception of the large olivine and pyrrhotite which are confirmed by electron diffraction as well.

The Ni-rich side of the sulfide has $\mathrm{Ni} / \mathrm{Fe}=0.3 \mathrm{by}$ at $\%, 2 \mathrm{wt} \% \mathrm{Co}$ and no $\mathrm{Mn}$. The Ni-poor side of the sulfide has $\mathrm{Ni} / \mathrm{Fe}=0.03$ by at $\%, 1 \mathrm{wt} \% \mathrm{Co}$, and no $\mathrm{Mn}$. On average $\mathrm{Ni} / \mathrm{Fe}=0.12$ by at $\%$. Figure $2 \mathrm{~A}$ shows that diffraction of the sulfide matches pyrrhotite $4 C$ zone 110 . The FWHM of the superlattice reflections $\left(0.44 \mathrm{~nm}^{-1}\right)$ is much wider than the lattice reflections $\left(0.22 \mathrm{~nm}^{-1}\right)$ which indicates that the sulfide is far out of equilibrium. Using the method of [Gainsforth] we find that the degree of equilibration matches sulfides grown by reaction of $\mathrm{H}_{2} \mathrm{~S}$ gas with metal at about $500{ }^{\circ} \mathrm{C}$. Faint reflections at $2 \AA$ coupled with a deficit of $\mathrm{S}$ by EDS likely indicate the presence of metal as well.

Brightfield imaging of the olivine (Figure 1A, "Ol") shows that it has a $50 \mathrm{~nm}$ damage rim where many defects are present. In addition, the neighboring sulfide contains a metal-rich rim of similar thickness.

[Jilly-Rehak] previously measured $\mathrm{O}$ isotopes and found that the silicates had a $\Delta^{18} \mathrm{O}=0 \%$. This is consistent with many silicates found in comets [Ogliore, Westphal], as well as FeO-rich silicates in type II chondrules [Schrader]. These observations are consistent with the silicates being formed or altered within our Solar System (i.e., not pre-solar).

Using the glass thermometer from [Putirka, Helz] we found a glass equilibration temperature between 920 $-1015^{\circ} \mathrm{C}$. As glass and sulfide are the most rapidly equilibrating phases in our aggregate, they should best constrain the final conditions of formation or alteration.

We also modeled the phases via MELTS [Smith, Ghiorso, Asimow] using the bulk composition of the fine silicates (Figure 1B) with added $\mathrm{Fe}+\mathrm{Ni}$ in the ratio found in the sulfide (Figure 1A). It was not possible to correctly model the higher temperature phases: olivine and pyroxene. At $\mathrm{fO}_{2}<\mathrm{IW}-3$, modeling predicts LIME olivine with $\mathrm{MnO}$ between 10-20 wt\%, and $\mathrm{FeO}<1 \mathrm{wt} \%$. At $\mathrm{fO}_{2}>\mathrm{IW}-3$ and $\mathrm{T}>1300$ 
$\mathrm{C}$ we could produce $\mathrm{MnO}$ near the experimental value of $0.8 \mathrm{wt} \%$ but the olivine was too $\mathrm{Fe}$ rich. Similarly, it was not possible to simultaneously match $\mathrm{Al}_{2} \mathrm{O}_{3}, \mathrm{FeO}$ and $\mathrm{CaO}$ in the $\mathrm{CPX}$. Both of these phases are clearly out of equilibrium. We could model approximately the correct glass compositions at nearly any $\mathrm{fO}_{2}$ only if $\mathrm{T}<1000{ }^{\circ} \mathrm{C}$. If the sulfide formed by sulfidation of metal, then the metal could only be modeled with the correct bulk Fe/Ni ratio near $\mathrm{fO}_{2}=\mathrm{IW}-1$.

Therefore we suggest the aggregate originally formed near IW-1 by sintering of relict silicates and metal near $1000{ }^{\circ} \mathrm{C}$. It later partially sulfidized at $\mathrm{T} \approx 500-1000{ }^{\circ} \mathrm{C}$. The second step could have occurred later in the same event or during a subsequent sulfidizing event.

[Joswiak] recently studied fine-grained kosmochloric pyroxenes associated with olivine, glass and sulfides from comet Wild 2. Preferential partitioning of Al, Ti to pyroxene and Mn to olivine indicated cogenetic formation. In our EA, $\mathrm{Al}$ and $\mathrm{Ti}$ do partition to pyroxene, but Mn behaves less predictably. Texturally, our fine-grained silicate region resembles Wild 2 material such as Arinna-A-1 [Joswiak, Fig 3] which suggests a relationship to other cometary material. [Schrader] examined agglomeratic olivine chondrules in CR meteorites and made a case that Wild 2 and AO chondrules both formed from AOA-like precursors. The low $\mathrm{T}$ formation of this aggregate fits will with the idea that fine grained aggregates were formed and then lightly heated by a gentle chondrule formation process. In this case, the heating should have been $\leq 1000{ }^{\circ} \mathrm{C}$ while still holding a high $\mathrm{fO}_{2}$ and/or $\mathrm{fS}_{2}$.

\begin{tabular}{|c|c|c|c|c|c|c|c|c|c|c|c|}
\hline Phase & $\mathrm{SiO}_{2}$ & $\mathrm{TiO}_{2}$ & $\mathrm{Al}_{2} \mathrm{O}_{3}$ & $\mathrm{Cr}_{2} \mathrm{O}_{3}$ & $\mathrm{MgO}$ & $\mathrm{FeO}$ & $\mathrm{CaO}$ & $\mathrm{MnO}$ & $\mathrm{Na}_{2} \mathrm{O}$ & $\mathrm{K} 2 \mathrm{O}$ & Mg\# \\
\hline Coarse Olivine & 36.84 & & & & 39.82 & 22.11 & & 1.23 & & & 76 \\
\hline Fine Olivine & 44.65 & & 0.26 & & 39.04 & 15.25 & & 0.80 & & & 82 \\
\hline Coarse CPX & 49.12 & 0.95 & & 6.57 & 13.80 & 7.69 & 20.90 & 0.97 & & & 76 \\
\hline Fine CPX & 56.30 & 0.33 & 5.05 & 4.31 & 13.49 & 4.12 & 14.14 & & 2.27 & & 83 \\
\hline Coarse OPX & 45.07 & & & 1.79 & 27.38 & 17.47 & 7.00 & 1.29 & & & 74 \\
\hline Fine Glass & 78.20 & & 20.02 & & 0.85 & 0.57 & & & & 0.38 & 73 \\
\hline
\end{tabular}

Table 1. Compositions of phases in Oxide Wt \%.

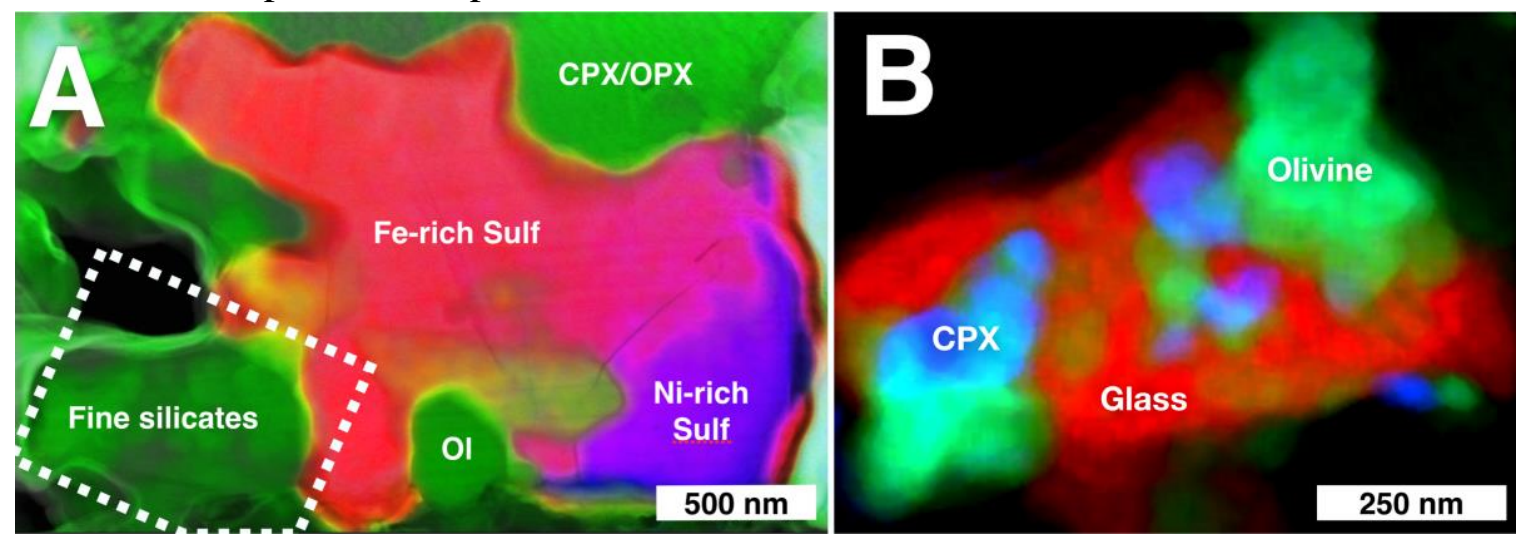

Figure 1. A) STEM/EDS view of a FIBed equilibrated aggregate (EA). Image is an LRGB with HAADF (luminance), $\mathrm{Fe}$ (red), $\mathrm{Mg}$ (green), and $\mathrm{Ni}$ (blue). Ol=Olivine, Sulf=sulfide, CPX=clinopyroxene. B) Zoomin on fine grained silicates in the EA. The phases are colored using NMF (see text): Glass (red), Olivine (green), CPX (blue). 

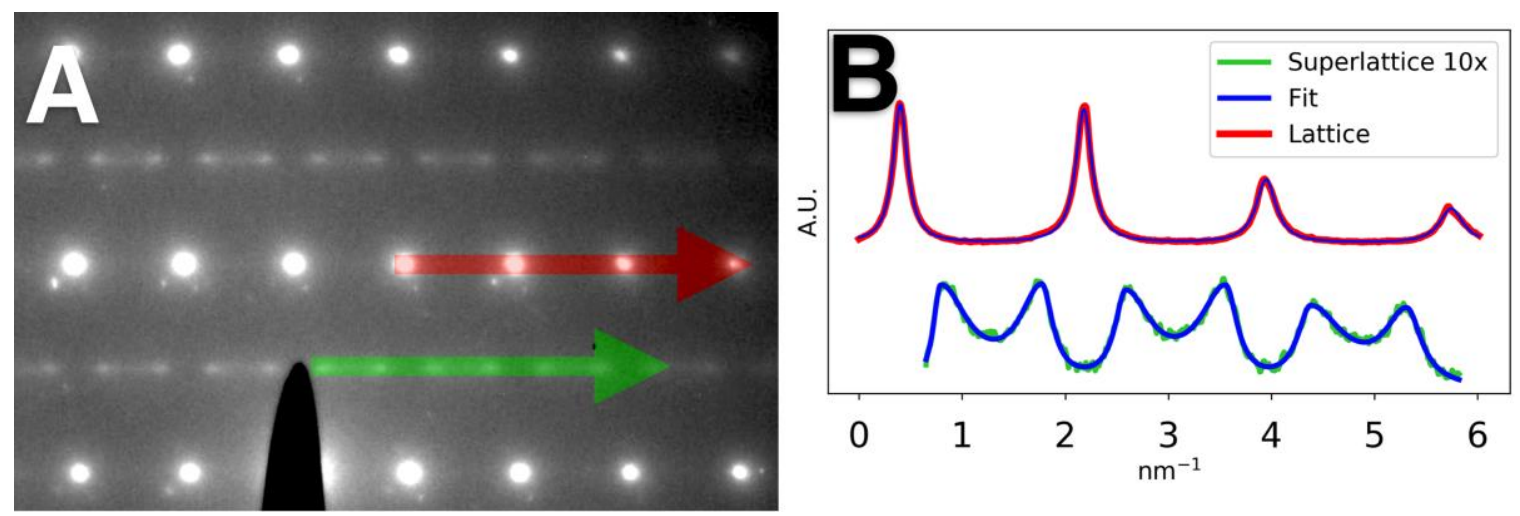

Figure 2. SAED down zone 110 of pyrrhotite 4C. The red arrow shows a trace across four lattice reflections while the green arrow shows a trace across 6 superlattice reflections. The traces are shown in B. B) Lattice (red) and superlattice (green) peak shapes with fits (blue) using split-Lorentzian peaks and after removal of a linear background. The amplitude of the superlattice reflections has been multiplied by 10. The FWHM of the superlattice reflections is about double that of the primary reflections indicating formation out of equilibrium (see text).

\section{References}

Asimow, P.D., and M.S. Ghiorso (1998), Algorithmic modifications extending MELTS to calculate subsolidus phase relations, American Mineralogist, 83 (9-10), 1127-1132.

Gainsforth, Z., et al. (2017). Insights into solar nebula formation of pyrrhotite from nanoscale disequilibrium phases produced by H2S sulfidation of Fe metal. American Mineralogist, 102, 1881-1893. http://doi.org/10.2138/am-2017-5848

Ghiorso, M.S., and R.O. Sack (1995), Chemical Mass-Transfer in Magmatic Processes IV. A Revised and Internally Consistent Thermodynamic Model for the Interpolation and Extrapolation of Liquid-Solid Equilibria in Magmatic Systems at Elevated-Temperatures and Pressures, Contributions to Mineralogy and Petrology, 119 (2-3), 197-212.

Jilly-Rehak, C. E., et al. (2019, March). Coordinated TEM and NanoSIMS Oxygen Isotope Analysis of Interplanetary Dust Particles Prepared by Focused Ion Beam. In Lunar and Planetary Science Conference (Vol. 50).

Joswiak, D. J., et al. (2009). Kosmochloric Ca-rich pyroxenes and FeO-rich olivines (Kool grains) and associated phases in Stardust tracks and chondritic porous interplanetary dust particles: Possible precursors to FeO-rich type II chondrules in ordinary chondrites. Lunar and Planetary Sciences Conference, 44(10), 1561-1588.

Putirka, K. D. (2008). Thermometers and Barometers for Volcanic Systems. Reviews in Mineralogy and Geochemistry, 69(1), 61-120. http://doi.org/10.2138/rmg.2008.69.3

Schrader, D. L., et al. (2018). The retention of dust in protoplanetary disks: Evidence from agglomeratic olivine chondrules from the outer Solar System. Geochimica Et Cosmochimica Acta, 223, 405-421. http://doi.org/10.1016/j.gca.2017.12.014

Smith, P. M., and P. D. Asimow (2005), Adiabat_1ph: A new public front-end to the MELTS, pMELTS, and pHMELTS models, Geochem. Geophys. Geosyst., 6, art. no. Q02004, doi:10.1029/2004GC000816. 